\title{
Defining prognostic factors in the elderly with community acquired pneumonia: a case controlled study of patients aged $\geqslant 75$ yrs
}

\author{
W-S. Lim, J.T. Macfarlane
}

\begin{abstract}
Defining prognostic factors in the elderly with community acquired pneumonia: a case controlled study of patients aged $\geqslant 75$ yrs. W.-S. Lim, J.T. Macfarlane. (C)ERS Journals Ltd 2001.

ABSTRACT: Severity assessment in the elderly with community acquired pneumonia (CAP) may be different compared with younger patients. In particular, age per se may not be of prognostic significance in older patients. A case-control study in 158 patients aged $\geqslant 75 \mathrm{yrs}$ with CAP was conducted to determine the factors associated with in-hospital mortality.

Cases were drawn from all patients aged $\geqslant 75$ yrs with CAP who died in 1997 in five hospitals in the mid-Trent region of the UK (Nottingham City Hospital, University Hospital Nottingham, Derby Royal Infirmary, Derby City General Hospital and Kings Hill Hospital). Controls were randomly selected from survivors also aged $\geqslant 75$ yrs. Factors associated with mortality were identified following a review of the medical casenotes and the contribution of these factors to mortality was determined using multivariate analysis.

Absence of fever, tachycardia and chest radiograph features of bilateral involvement or an effusion were independently associated with mortality on multivariate analysis. The British Thoracic Society (BTS) severity rule was $50 \%$ sensitive and $64 \%$ specific in predicting death while the modified BTS rule displayed $67 \%$ sensitivity and $58 \%$ specificity.

Age was not significantly associated with mortality in this group of patients aged $\geqslant 75$ yrs. Similarly, the clinical features employed in the British Thoracic Society rule, namely respiratory rate, diastolic blood pressure and blood urea, were not of prognostic significance and the rule itself performed poorly. The modified British Thoracic Society rule performed better.
\end{abstract}

Eur Respir J 2001; 17: 200-205.

Respiratory Medicine, Nottingham City Hospital, Hucknall Road, Nottingham, UK.

Correspondence: J.T. Macfarlane, Respiratory Medicine Unit, Medical Research Centre, City Hospital, Hucknall Road, Nottingham NG5 1PB UK

Keywords: community acquired pneumonia

elderly

pneumonia

prognosis

respiratory infections

severity assessment

Received: January 132000

Accepted after revision April 132000

This work was supported by Hoechst Marion Roussel (Uxbridge, Middlesex, UK).
There are over a quarter of a million episodes of community acquired pneumonia (CAP) annually in the UK, half involving patients $>64 \mathrm{yrs}$ of age [1]. Mortality from CAP ranges from 5-18\%, with elderly patients having a higher mortality [2]. Over the past 20 yrs, numerous studies have examined the prognostic factors associated with mortality in CAP. The 1982/ 1983 British Thoracic Society (BTS) multicentre study represented the first major effort in this field and identified increased respiratory rate, raised urea and hypotension as important adverse prognostic factors [3]. However, that study did not include patients aged $>74$ yrs and there is now growing evidence that a different set of prognostic factors may operate in older patients. In particular, recent studies have suggested that increasing age is not associated with mortality in the elderly $[4,5]$. Unfortunately, such studies have been small scale and have not examined a substantial number of patients aged $\geqslant 75$ yrs with CAP which constitute about $40 \%$ of the population of patients with CAP admitted to hospital in the UK (unpublished data).

A case-control study in patients $\geqslant 75$ yrs of age with
CAP was conducted to determine the factors associated with in-hospital mortality and to derive appropriate threshold values for the prognostic variables thus identified.

\section{Method}

Adults aged $\geqslant 75$ yrs of age admitted 1 January 1997-31 December 1997 to five hospitals in the midTrent region of England (Nottingham City Hospital, University Hospital Nottingham, Derby Royal Infirmary, Derby City General Hospital and King's Mill Hospital) with a diagnosis of CAP were identified from hospital records. Cases comprised of patients who died during hospital admission. These cases formed part of a larger study reported elsewhere [6]. For this analysis, an equal number of controls were drawn from a random sample of those patients also aged $\geqslant 75 \mathrm{yrs}$, who survived. In all instances where patients were admitted to hospital more than once within the study period, only the first episode was taken into consideration. CAP was defined by the presence of shadowing on an 
admission chest radiograph (CXR) consistent with infection, inpatient treatment for pneumonia and a discharge/death diagnosis of pneumonia. Patients discharged from hospital in the previous 10 days were excluded as were patients with tuberculosis, lung cancer and human immunodeficiency virus (HIV). Immunocompromised patients, those with neutropenia or on chemotherapy, were also excluded. Treatment with oral steroids was not a cause for exclusion. Ethical approval was obtained from the local Ethics Committees of all the hospitals involved.

Patient demographic features were recorded according to a standard questionnaire. Comorbid illnesses were defined as the presence of co-existing cardiac failure, ischaemic heart disease, hypertension, atrial fibrillation, chronic lung disease, chronic liver disease, chronic renal disease, cancer, past cerebrovascular disease, cognitive impairment, diabetes mellitus and rheumatological disorders, excluding osteoarthiritis, for which the patient was under active medical supervision or was receiving treatment at the time of hospital admission. Data for pulse, blood pressure, respiratory rate, the presence of confusion and oxygen saturation on hospital admission was taken as the first recorded values within $24 \mathrm{~h}$ of admission. Mental status was taken to be normal unless otherwise recorded in the medical notes. Documentation of confusion, a Mental Test Score of $\leqslant 8$ out of 10 or disorientation in person, time or place was accepted as evidence of an altered mental state on admission. The presence of urinary incontinence was based on patient history documented by either medical or nursing staff. Only results of investigations performed within $24 \mathrm{~h}$ of admission were studied. These included haemoglobin, white cell count, platelet count, haematocrit, urea, creatinine, sodium, potassium, alkaline phosphatase, liver enzymes, albumin and pulse oximetry.

\section{Statistical analysis}

Data were analysed using SPSS Version 8.0 for windows (Chicago, IL, USA). Sixteen variables were selected based on evidence in the literature and results from other studies, and were examined for association with mortality. The majority of these variables were continuously distributed, and to avoid any assumptions regarding the form of the relationship of these variables to mortality, each was initially re-expressed as four level factors using quartile cut-offs. The univariate association of each of the resultant variables to mortality was analysed by logistic regression. Statistical significance was assessed by testing for a difference in odds (binary variables) or a trend in odds across categories (categorical variables).

Variables which were significantly $(\mathrm{p}<0.05)$ related to mortality in univariate analysis were entered simultaneously into a multiple logistic regression. Continuous variables were recategorized into binary factors, if appropriate, using threshold values determined by examination of the univariate odds ratios (OR). Where the threshold value suggested by the analyses differed from those implicit in one or more of the existing severity criteria, the effect of changing the threshold was investigated. All remaining variables were then tested, one at a time, to confirm their contribution to the multivariate model. Results of multivariate analysis are reported as OR with $95 \%$ confidence intervals and $\mathrm{p}$-values, taking $\mathrm{p}<0.05$ as the level of statistical significance.

The sensitivities, specificities, positive predictive values and negative predictive values of the BTS rule [3] and modified BTS rule [7] were calculated and compared.

\section{Results}

During 1997, 1,253 patients with a primary discharge diagnosis of pneumonia were recorded at the five study hospitals, $519(41 \%)$ of whom were aged $\geqslant 75$ yrs. Of the $114(22 \%)$ patients aged $\geqslant 75$ yrs who died, 78 $(68 \%)$ met the study criteria for CAP. The mean \pm SD age of cases was $83.8 \pm 5.4$ yrs compared with a mean \pm SD age of $84.4 \pm 5.4$ yrs for the 78 controls. Fifty-six $(72 \%)$ of the cases and $55(71 \%)$ of the controls had $\geqslant 1$ comorbid illnesses. There was no difference in the number of cases and controls who had $\geqslant 3$ comorbid illnesses.

More cases were nursing or residential home residents at the time of hospital admission (24 (31\%) cases compared to $14(18 \%)$ controls). However, this difference was not statistically significant.

Of the 16 variables examined for an association with mortality, seven were found to be significant on univariate analysis $(\mathrm{p}<0.05)$. These were temperature, pulse rate, respiratory rate, blood urea, presence of confusion and CXR changes indicating a pleural effusion or bilateral involvement (tables 1 and 2). Threshold values for those continuous variables significantly associated with mortality based on examination of the univariate $\mathrm{OR}$ were temperature $<37^{\circ} \mathrm{C}$, urea $\geqslant 14 \mathrm{mmol} \cdot 1^{-1}$, respiratory rate $>24$ breaths. min $^{-1}$ and pulse rate $\geqslant 95$ beats $\cdot \min ^{-1}$.

These variables were entered into a multiple logistic regression model taking the CXR changes as a single variable. Only temperature $<37^{\circ} \mathrm{C}$, pulse $\geqslant 95 \cdot \mathrm{min}^{-1}$ and CXR features of an effusion or bilateral involvement were identified as independent predictors of mortality (table 3 ). These three factors were present in $57 \%, 62 \%$ and $22 \%$ of cases respectively compared with $27 \%, 37 \%$ and $6 \%$ of controls. Using a combination of these factors to predict mortality lacked either sensitivity or specificity depending on the number of factors considered (table 4). Using cut-off values of temperature $\leqslant 37^{\circ} \mathrm{C}$ and pulse $\geqslant 100 \cdot \mathrm{min}^{-1}$ produced similar results.

Similarly, the BTS and modified BTS rules did not perform well although sensitivity of the modified BTS rule (sensitivity $67 \%$, specificity $58 \%$ ) was much better than the BTS rule (sensitivity $50 \%$, specificity $64 \%$ ) (table 5).

\section{Discussion}

In this study of patients aged $\geqslant 75 \mathrm{yrs}$, age per se was not identified as an independent predictor of mortality. 
Table 1.-Association of clinical features with mortality on univariate analysis

\begin{tabular}{|c|c|c|c|c|c|}
\hline Variable & No. with complete data & Cases & Controls & OR & $95 \% \mathrm{CI}$ \\
\hline Age yrs & 156 & & & & \\
\hline$\leqslant 80$ & & 22 & 21 & Reference & \\
\hline $81-83$ & & 16 & 19 & 0.77 & $0.31-1.88$ \\
\hline $84-88$ & & 25 & 21 & 1.18 & $0.49-2.82$ \\
\hline$\geqslant 89$ & & 15 & 17 & 0.74 & $0.31-1.77$ \\
\hline Nursing/residential home & 156 & & & 2.03 & $0.96-4.31$ \\
\hline residence & & 24 & 14 & & \\
\hline No comorbid illness & 156 & 20 & 21 & 0.94 & $0.46-1.91$ \\
\hline Urinary incontinence & 156 & 7 & 4 & 1.82 & $0.51-6.50$ \\
\hline Mental Confusion & 156 & 37 & 23 & 2.16 & $1.12-4.17$ \\
\hline Temperature, ${ }^{\circ} \mathrm{C}$ & 155 & & & & \\
\hline$\geqslant 37.9$ & & 12 & 29 & Reference & \\
\hline $37.1-37.8$ & & 14 & 18 & 1.84 & $0.70-4.9$ \\
\hline $36.3-37.0$ & & 22 & 18 & 3.00 & $1.17-7.66$ \\
\hline$\leqslant 36.2$ & & 30 & 12 & 6.13 & $2.32-16.17$ \\
\hline Pulse, beats $\cdot \min ^{-1}$ & 156 & & & & \\
\hline$\leqslant 80$ & & 17 & 28 & Reference & \\
\hline $81-94$ & & 13 & 20 & 1.07 & $0.43-2.69$ \\
\hline $95-110$ & & 30 & 17 & 2.91 & $1.25-6.78$ \\
\hline$\geqslant 111$ & & 18 & 13 & 2.28 & $0.90-5.80$ \\
\hline Systolic blood pressure, $\mathrm{mmHg}$ & 156 & & & & \\
\hline$\geqslant 150$ & & 20 & 19 & Reference & \\
\hline $131-149$ & & 18 & 17 & 1.00 & $0.40-2.51$ \\
\hline $121-130$ & & 16 & 16 & 0.95 & $0.37-2.42$ \\
\hline$\leqslant 120$ & & 24 & 26 & 0.88 & $0.38-2.03$ \\
\hline Diastolic blood pressure, $\mathrm{mmHg}$ & 156 & & & & \\
\hline$\geqslant 81$ & & 15 & 15 & Reference & \\
\hline $71-80$ & & 19 & 24 & 0.79 & $0.31-2.02$ \\
\hline $61-70$ & & 22 & 21 & 1.05 & $0.41-2.66$ \\
\hline$\leqslant 60$ & & 22 & 18 & 1.22 & $0.47-3.16$ \\
\hline Respiratory rate, $\min ^{-1}$ & 137 & & & & \\
\hline$\leqslant 20$ & & 17 & 32 & Reference & \\
\hline $21-24$ & & 12 & 12 & 1.94 & $0.71-5.28$ \\
\hline $25-30$ & & 21 & 11 & 3.70 & $1.44-9.53$ \\
\hline$\geqslant 31$ & & 19 & 15 & 2.45 & $1.00-6.08$ \\
\hline Oxygen saturation, \% & 99 & & & & \\
\hline$\geqslant 96$ & & 7 & 32 & Reference & \\
\hline $93-95$ & & 6 & 12 & 0.54 & $0.15-2.00$ \\
\hline $89-92$ & & 14 & 11 & 1.60 & $0.49-5.22$ \\
\hline$\leqslant 88$ & & 16 & 15 & 2.74 & $0.81-9.31$ \\
\hline
\end{tabular}

OR: odds ratio; CI: confidence interval.

Most studies investigating severity prognostic factors in adult CAP have involved patient cohorts with a full age range or an upper age limit. These studies provide strong evidence for the association of increasing age with mortality as is reflected in the weighting given to age in the pneumonia severity index (PSI) proposed by FINE et al. [8]. For example, when applied to this study, the vast majority of patients were stratified to PSI Risk Classes IV and V (47\% and $49 \%$ of cases respectively and $44 \%$ and $42 \%$ of controls), mainly as a consequence of age.

In contrast, studies conducted exclusively in older patients have yielded conflicting results with regards the association of advanced age with mortality. CONTE et al. [9] recent large retrospective study conducted in the USA using a Medicare database of patients aged $\geqslant 65$ yrs identified age $\geqslant 85 \mathrm{yrs}$ as an independent prognostic factor [9]. However, the overall mortality in that cohort of patients was only $9 \%$; which was much lower when compared to other studies where reported mortality rates in elderly patients with CAP have ranged from $14-33 \%[5,10,11]$. Conversely, prospective studies of CAP in the elderly conducted in Europe have tended to find no association between age and mortality $[4,5,10,11]$. The present study supports this view. One possible explanation for this observation is that within the elderly population, the more frail tend to die at younger ages, hence the older survivors tend to be healthier. Support for this can be found in HoRIUCHI and WILMOTH's [12] large longitudinal study of the relationship of mortality with age decades in two large population cohorts, one Swedish and the other Japanese [12]. They showed that all cause mortality increased with increasing age until around the age of 75 yrs. Thereafter, a deceleration in the rate of mortality was noted. This finding remained true when only deaths from pneumonia were considered.

The present results do not suggest an independent effect of comorbid illnesses on mortality. There was no difference in the presence of or extent of comorbid illnesses in cases compared to controls. Unfortunately, comparison with other studies is hampered by lack of a 
Table 2. - Association of initial investigations with mortality on univariate analysis

\begin{tabular}{|c|c|c|c|c|c|}
\hline Variable & No. with complete data & Cases & Controls & OR & $95 \% \mathrm{CI}$ \\
\hline White cell count, $\times 10^{9} \cdot \mathrm{L}^{-1}$ & 152 & & & & \\
\hline$\leqslant 8.20$ & & 17 & 21 & Reference & \\
\hline $8.21-11.90$ & & 14 & 24 & 0.75 & $0.30-1.89$ \\
\hline $11.91-15.70$ & & 19 & 19 & 1.10 & $0.44-2.76$ \\
\hline$\geqslant 15.71$ & & 24 & 14 & 2.47 & $0.96-6.34$ \\
\hline Urea, $\mathrm{mmol} \cdot \mathrm{L}^{-1}$ & 152 & & & & \\
\hline$\leqslant 7.13$ & & 14 & 24 & Reference & \\
\hline $7.14-9.6$ & & 17 & 23 & 1.27 & $0.51-3.15$ \\
\hline $9.7-13.8$ & & 17 & 20 & 1.37 & $0.54-3.48$ \\
\hline$\geqslant 13.9$ & & 26 & 11 & 4.21 & $1.61-11.01$ \\
\hline Creatinine, $\mu \mathrm{mol} \cdot \mathrm{L}^{-1}$ & 152 & 20 & & & \\
\hline$\leqslant 89$ & & 14 & 25 & Reference & \\
\hline $89.1-112.5$ & & 17 & 20 & 1.52 & $0.61-3.81$ \\
\hline $112.6-151.5$ & & 22 & 16 & 2.46 & $0.98-6.15$ \\
\hline$\geqslant 151.6$ & & 21 & 17 & 2.21 & $0.88-5.51$ \\
\hline Albumin, $\mathrm{g} \cdot \mathrm{L}^{-1}$ & 119 & & & & \\
\hline$\geqslant 35.1$ & & 8 & 17 & Reference & \\
\hline $32.1-35$ & & 14 & 15 & 1.98 & $0.65-6.03$ \\
\hline $28.1-32.0$ & & 21 & 13 & 3.43 & $1.16-10.19$ \\
\hline$\leqslant 28.0$ & & 16 & 15 & 2.27 & $0.76-6.78$ \\
\hline CXR, bilateral involvement & 155 & 12 & 4 & 3.42 & $1.05-11.11$ \\
\hline CXR, pleural effusion & 156 & 9 & 1 & 10.00 & $1.24-80.62$ \\
\hline
\end{tabular}

CXR: chest radiograph; OR: odds ratio; CI: confidence interval.

consistent definition of "comorbid illnesses" and difficulties in grading the severity of each of these illnesses. Nevertheless, there are now at least five other studies of CAP in the elderly, two conducted in Intensive Care Units, which have not found any association between comorbid illness and mortality $[4,5,10,11,13]$.

Respiratory rate, blood urea and confusion were not found to be independently associated with mortality; the key factors that comprise the BTS mortality severity score. Absence of pyrexia was found to be an important prognostic factor confirming the finding of other studies which used only univariate analysis $[10,14$, 15] or a small number of patients [11]. Absence of a febrile response to infection may reflect an impaired immune response. Elderly patients have been reported to have a depressed immune response to infection and may be particularly at risk of succumbing to overwhelming infection [16].

The value of pulse rate as an independent predictor of mortality in CAP was first described by FINE et al. [17]. In their study of adults of all ages with CAP, a rate of $\geqslant 125 \cdot \mathrm{min}^{-1}$ was used as the cut-off level whereas the present study identified a rate of $\geqslant 95 \cdot \mathrm{min}^{-1}$ as indicating a high risk of mortality. The importance of this difference in cut-off value is unclear. Tachycardia is an easily and readily measured clinical sign but is a nonspecific finding influenced by many factors. Hence the clinical implication of tachycardia on its own, whatever the cut-off level, is less obvious though it may be useful in identifying severely ill patients.

It was shown that bilateral CXR changes or presence of an effusion are predictors of mortality. This finding is consistent with reports from other studies $[5,18]$. In the elderly where presenting features are often nonspecific, the CXR affords the clinician objective evidence of the extent of infection. Thus although only a small proportion $(22 \%)$ of cases had CXR signs of bilateral involvement or an effusion, this is likely to be an important and valuable clinical feature in the assessment of disease severity.

The BTS and modified BTS rules performed poorly in the elderly. Similarly, the large retrospective study by CONTE et al. [9] and more recently a prospective study by EwIG et al. [19] of 168 patients $\geqslant 65$ yrs old admitted to a primary care hospital in Germany, found the BTS rule to have a sensitivity of only $50.3 \%$ and $65 \%$ respectively $[9,19]$. As the BTS rule was derived from the 1987 BTS multicentre CAP study which only included adults aged $18-74$ yrs [3, 20], it is perhaps not surprising that this rule has not been shown to perform as well in older patients. In a derivation study by NEILL

Table 3. - Association of clinical variables with mortality on multivariate analysis

\begin{tabular}{llcc}
\hline Clinical feature & OR & $95 \%$ CI & p-value \\
\hline Temperature $<37{ }^{\circ} \mathrm{C}$ & 3.7 & $1.6-8.7$ & $<0.01^{*}$ \\
Pulse $\geqslant 95 \cdot \mathrm{min}^{-1}$ & 3.1 & $1.3-7.2$ & $<0.01^{*}$ \\
Respiratory rate $>24 \cdot \mathrm{min}^{-1}$ & 1.8 & $0.8-4.2$ & 0.18 \\
Confusion & 1.8 & $0.8-4.1$ & 0.16 \\
Urea $\geqslant 14 \mathrm{mmol} \cdot \mathrm{L}^{-1}$ & 1.8 & $0.7-4.8$ & 0.26 \\
CXR, bilateral changes or pleural effusion & 4.1 & $1.3-13.2$ & $0.02^{*}$ \\
\hline
\end{tabular}

OR: odds ratio; CI: confidence interval. $*$ : $\mathrm{p}<0.05$. 
Table 4.-Using temperature, pulse rate and chest radiograph changes to predict mortality

No. of Cases Controls Sensitivity Specificity PPV NPV factors

\begin{tabular}{rrrrrrr}
\hline$\geqslant 1$ & 68 & 49 & 88 & 36 & 58 & 74 \\
$\geqslant 2$ & 37 & 7 & 48 & 91 & 82 & 63 \\
3 & 3 & 0 & 4 & 100 & 100 & 50 \\
\hline
\end{tabular}

Data are presented as \%. PPV: positive predictive value; NPV: negative predictive value.

et al. [7], the modified BTS rule had a sensitivity of 95\% and specificity of $71 \%$. That study did not have an upper age limit (range 18-97 yrs) but the mean age of the study cohort was only 58 yrs. Hence the modified BTS rule cannot be considered to have been adequately assessed in elderly patients in that study. Validation and retrospective studies are recognized as describing poorer performances for prediction rules and would partly explain the results obtained compared to the prospective derivation studies for the BTS and modified BTS rules. However, the present results, together with the evidence from other studies, also suggest that these prediction rules perform less well in patients aged $\geqslant 75$ yrs.

Although apyrexia, tachycardia and the presence of adverse CXR changes at the time of hospital admission was found to be independently associated with mortality, the frequency of these features in survivors and nonsurvivors was not sufficiently different to enable their use as discriminating factors. Predicting prognosis in these patients is therefore difficult. In view of the wide spectrum of pre-existing health in this population, ranging from full independence to complete dependence, some measure of health status is likely to be an important element in any prognostic model [21]. Lessons learnt from the speciality of oncology, where functional status plays a key role in risk assessment, should possibly be tested in and applied to older patients with CAP [22, 23].

The main weakness of this study is its retrospective design. Collection of some data was therefore, incomplete. In some cases, comorbid illnesses such as unrecognized chronic obstructive airways disease may have remained undiagnosed. However there is no reason to expect this to have a large impact on the findings as any comorbid illness that remained undiagnosed during hospital admission is unlikely to have been severe. The authors were unable to examine the contribution of blood gases results to mortality as

Table 5.-Performance of the British Thoracic Society (BTS) and modified BTS severity prediction rules*

\begin{tabular}{|c|c|c|c|c|}
\hline $\begin{array}{l}\text { Prediction } \\
\text { rule }\end{array}$ & Sensitivity & Specificity & PPV & NPV \\
\hline $\begin{array}{l}\text { BTS } \\
\text { Mod }\end{array}$ & $32 /$ & $44 / 69$ (64) & $32 / 57(56)$ & $44 / 76(58)$ \\
\hline BTS rule & $43 / 64(67)$ & $40 / 69(58)$ & $43 / 72(60)$ & $40 / 61(66)$ \\
\hline
\end{tabular}

*: Data are presented as n (\%). Based on 64 cases and 69 controls with complete data for assessment of the respective rules. only 35 cases and 36 controls had blood gas measurements recorded. This reflects the practice in many UK based hospitals, of only testing blood gases if felt to be clinically indicated. Based on the data available, no association between oxygen tension in arterial blood and mortality was noted $(\mathrm{p}=0.2)$. As the proportion of cases and controls with missing data was similar, the authors believe this weakness does not invalidate the results. Conversely, the case-control design allowed for the study of a large number of cases, thus reducing the problem of spurious associations arising from the overfitting of data during multivariate analysis [24].

\section{Conclusion}

To conclude, in patients aged $\geqslant 75 \mathrm{yrs}$, mortality from community acquired pneumonia was found to be independently associated with an absence of fever, a tachycardia and chest radiograph features of bilateral involvement or a pleural effusion. None of the clinical features employed in the British Thoracic Society rule were of prognostic significance and the rule itself performed poorly. Age was not significantly associated with mortality. Management decisions in this group of patients should be determined by clinical judgement and not, therefore, be governed by age or use of the British Thoracic Society criteria alone.

Acknowledgements. The authors would like to thank S. Lewis for insightful statistical advice.

\section{References}

1. Guest JF, Morris A. Community acquired pneumonia: the annual cost to the National Health Service in the UK. Eur Resp J 1970; 10: 1530-1534.

2. Fine MJ, Smith MA, Carson CA, Mutha SS, Sankey SS, Weissfeld LA, Kapoor WN. Prognosis and outcomes of patients with community-acquired pneumonia. A meta-analysis. JAMA 1996; 275: $134-141$.

3. Anonymous. Community-acquired pneumonia in adults in British hospitals in 1982-1983: a survey of aetiology, mortality, prognostic factors and outcome. The British Thoracic Society and the Public Health Laboratory Service. $Q$ J Med 1987; 62: 195-220.

4. Rello J, Rodriguez R, Jubert P, Alvarez B. Severe community-acquired pneumonia in the elderly: Epidemiology and prognosis. Clin Infect Dis 1996; 23: $723-728$.

5. Riquelme R, Torres A, El-Ebiary $\mathrm{M}$, et al. Community-acquired pneumonia in the elderly: Amultivariate analysis of risk and prognostic factors. Am J Respir Criti Care Med 1996; 154: $1450-1455$.

6. Lim WS, Lewis S, Macfarlane JT. Severity prediction rules in community acquired pneumonia: a validation study. Thorax 2000; 55: 219-223.

7. Neill AM, Martin IR, Weir R, et al. Community acquired pneumonia: aetiology and usefulness of 
severity criteria on admission. Thorax 1996; 51: $1010-$ 1016.

8. Fine MJ, Auble TE, Yealy DM, et al. A prediction rule to identify low-risk patients with community-acquired pneumonia. N Engl J Med 1997; 336: $243-250$.

9. Conte HA, Chen YT, Mehal W, Scinto JD, Quagliarello VJ. A prognostic rule for elderly patients admitted with community-acquired pneumonia. Am J Med 1999; 106: 20-28.

10. Venkatesan P, Gladman J, Macfarlane JT, et al. A hospital study of community acquired pneumonia in the elderly. Thorax 1990; 45: 254-258.

11. Janssens JP, Gauthey L, Herrmann F, Tkatch L, Michel JP. Community-acquired pneumonia in older patients. J Am Geriatric Soc 1996; 44: 539-544.

12. Horiuchi S, Wilmoth JR. Deceleration in the age pattern of mortality at older ages. Demography 1998; 35: $391-412$.

13. Leroy O, Devos P, Guery B, et al. Simplified prediction rule for prognosis of patients with severe community-acquired pneumonia in ICUs. Chest 1999; 116: $157-165$.

14. Starczewski AR, Allen SC, Varga E, Lye M. Clinical prognostic indices of fatality in elderly patients admitted to hospital with acute pneumonia. Age Ageing 1988; 17: $181-186$.

15. Ahkee S, Srinath L, Ramirez J. Community-acquired pneumonia in the elderly: association of mortality with lack of fever and leukocytosis. Southern Med J 1997; 90: $296-298$.

16. Schneider EL. Infectious diseases in the elderly. Ann Intern Med 1983; 98: 395-400.

17. Fine MJ, Hanusa BH, Lave JR, et al. Comparison of a disease-specific and a generic severity of illness measure for patients with communityacquired pneumonia. J Gen Intern Med 1995; 10: $359-368$.

18. Hasley PB, Albaum MN, Li YH, et al. Do pulmonary radiographic findings at presentation predict mortality in patients with community-acquired pneumonia? Arch Intern Med 1996; 156: 2206-2212.

19. Ewig S, Kleinfeld T, Bauer T, Seifert K, Schafer H, Goke N. Comparative validation of prognostic rules for community-acquired pneumonia in an elderly population. Eur Respir J 1999; 14: 370-375.

20. The British Thoracic Society. Guidelines for the management of community-acquired pneumonia in adults admitted to hospital. Br J Hosp Med 1993; 49: $346-350$.

21. Rockwood K, Stadnyk K, MacKnight C, McDowell I, Hebert R, Hogan DB. A brief clinical instrument to classify frailty in elderly people. Lancet 1999; 353 : 205-206.

22. Paesmans M, Sculier JP, Libert P, et al. Prognostic factors for survival in advanced non-small-cell lung cancer: univariate and multivariate analyses including recursive partitioning and amalgamation algorithms in 1,052 patients. The European Lung Cancer Working Party. J Clin Oncol 1995; 13: 1221 - 1230.

23. Extermann M, Overcash J, Lyman GH, Parr J, Balducci L. Comorbidity and functional status are independent in older cancer patients. $J$ Clin Oncol 1998; 16: $1582-1587$.

24. Concato J, Feinstein AR, Holford TR. The risk of determining risk with multivariable models. Ann Int Med 1993; 118: $201-210$. 